\title{
Evidence-based management to regulate the impact of tourism at a key marine turtle rookery on Zakynthos Island, Greece
}

\author{
Kostas A. Katselidis, Gail Schofield, Giorgos Stamou \\ Panayotis Dimopoulos and John D. Pantis
}

\begin{abstract}
This study evaluates how key beach features influence suitability for nesting by Endangered loggerhead marine turtles Caretta caretta at an internationally important rookery on Zakynthos Island, Greece. During 2007-2009 we assimilated information on beach structure (elevation above sea level and width), the distribution of all nesting (turtle tracks that resulted in nests) and nonnesting (turtle tracks that did not result in nests) turtle emergences from the sea along $6 \mathrm{~km}$ of beach, nest placement parameters (distance from sea and elevation above sea level), and beach use by visitors. We found that turtles preferentially emerged on steeper sections of beach, with higher nesting densities occurring on the most environmentally stable beaches. Elevation was a more reliable indicator of nest placement ( $1 \mathrm{~m}$ above sea level) than distance to shore. However, because nests on steeper slopes are located closer to shore, the risk of damage by tourism is increased in such areas. We calculated a potential $36 \%$ overlap of natural nest locations with use of the beach by tourists; however, the recorded overlap was $7 \%$ because of existing management protocols. This overlap could be further reduced by focusing conservation effort (i.e. further restricting use by people) on beach sections with the steepest inclines. For example, slopes of $>22^{\circ}$ comprise $1 \mathrm{~km}$ of total beach area annually, the closure of which (above the immediate shoreline to allow passage) would completely protect $50 \%$ of nests. This study shows the value of evidencebased management as a practical scientific tool to conserve threatened species in dynamic protected areas that are of both environmental and economic importance.
\end{abstract}

Keywords Caretta caretta, coastal development, dispersal, global climate change, heterogeneous environments, marine turtle, nest site selection, science-based management

Kostas A. KaTSELIDIS ${ }^{*}$ (Corresponding author) and Panayotis Dimopoulos Department of Environmental and Natural Resources Management, University of Ioannina, G. Seferi 2, GR-30100 Agrinio, Greece. E-mail kostason@gmail.com

GAIL SCHOFIELD Institute of Environmental Sustainability, Swansea University, Swansea, UK

Giorgos Stamou and John D. PANTis School of Biology, Aristotle University of Thessaloniki, Thessaloniki, Greece

*Also at: National Marine Park of Zakynthos, Zakynthos, Greece

Received 28 November 2011. Revision requested 13 February 2012.

Accepted 13 March 2012. First published online 24 July 2013.

\section{Introduction}

G vidence-based conservation management is essential $\mathrm{C}_{\text {in dynamic environments that require constant re- }}$ evaluation in response to changing conditions (e.g. Sutherland et al., 2004; Pullin \& Knight, 2009). Recent studies have shown the utility of dynamic protected areas at local and regional scales in terrestrial and marine environments (e.g. Howell et al., 2008; Hooker et al., 2011), facilitating both economic needs and environmental protection (Howell et al., 2008; Pearce et al., 2008). However, although scientific evidence is available to inform conservation practice (e.g. Pullin \& Knight, 2009; Hooker et al., 2011), static forms of conservation practice based on experience, precaution or anecdotal information remain common (e.g. Hyrenbach et al., 2000; Thompson et al., 2000; Schofield et al., 2010).

Beaches are of both economic and environmental importance (Arianoutsou, 1988; James, 2000; Schlacher et al., 2007), and effective beach management requires regular seasonal and/or annual re-evaluation because beaches are constantly being reshaped by wave action (Kamel \& Mrosovsky, 2004) and anthropogenic activities (Weishampel et al., 2003). Conservation efforts for loggerhead marine turtles Caretta caretta, categorized as Endangered on the IUCN Red List (Marine Turtle Specialist Group, 1996), tend to focus on nesting beaches, where reproductive output may be assessed and protected (e.g. Hays et al., 1995). Numerous studies have identified the environmental parameters required for successful beach selection, nest site selection and egg development (e.g. Carr \& Ogren, 1960; Hays et al., 1995; Wood \& Bjorndal, 2000; Fuentes et al., 2010).

Human threats may potentially influence offspring phenotype or cause direct mortality of marine turtles (e.g. Mortimer, 1990; Pfaller et al., 2008) through shading (e.g. beach furniture), compaction (e.g. foot or vehicular traffic), or digging/piercing (e.g. umbrellas) of unmarked nests. However, this information has not yet been used to resolve conflicting issues between safeguarding marine turtle nests and recreational demands (James, 2000). However, guidelines and criteria based on scientific research are essential to facilitate the implementation and evaluation of the effectiveness of management options (e.g. Sutherland et al., 2004; Pullin \& Knight, 2009).

Here, we develop evidence-based management recommendations for the nesting beaches of an internationally 


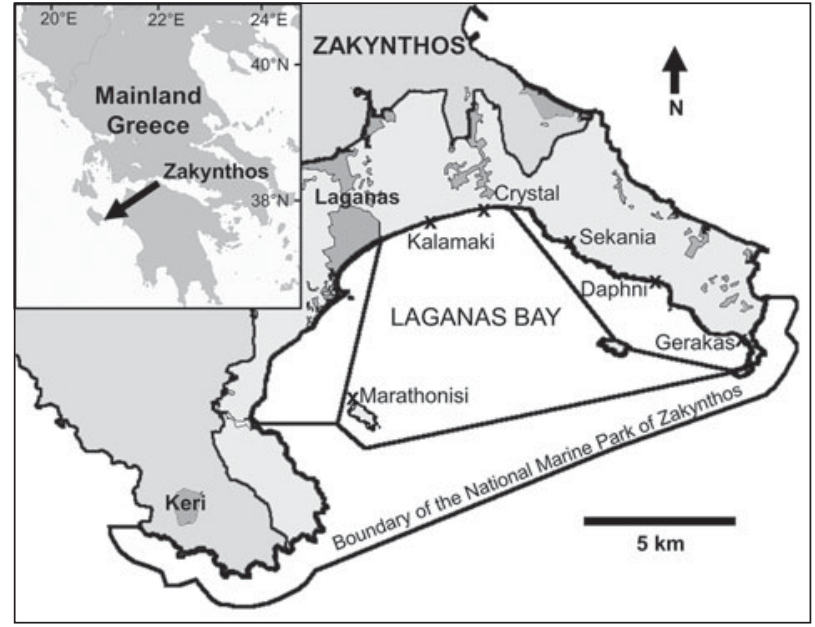

FIG. 1 The marine turtle breeding area of Laganas Bay on Zakynthos Island, showing the locations of the six nesting beaches (Marathonisi, Kalamaki, Crystal, Sekania, Daphni and Gerakas). Marine protection zones B and C allow boating at $6 \mathrm{~km} \mathrm{~h}^{-1}$; boating is prohibited in zone A. The inset shows the location of Zakynthos Island off the south-west coast of mainland Greece.

important loggerhead turtle rookery on Zakynthos, Greece, which is visited by several hundred thousand tourists each summer (May-October), when marine turtle nesting, nest incubation and hatching occur (Arianoutsou, 1988; Margaritoulis, 2005; Schofield et al., 2009). Both elevation (Wood \& Bjorndal, 2000) and beach width (Mazaris et al., 2006) have been suggested as the major regulating factors for nest placement by loggerhead turtles. We investigate which of these two parameters has the greatest influence on emergence and nesting location, and hence the greatest utility for management. We then evaluate the overlap of tourism with nesting parameters, to provide practical, science-based suggestions to reduce anthropogenic pressure. Finally, we discuss the value of evidence-based management as a tool for regulating conservation management of threatened species in dynamic protected areas that are of both environmental and economic importance.

\section{Study area and species}

The National Marine Park of Zakynthos lies in Laganas Bay on the Greek island of Zakynthos (Fig. 1). It hosts the largest documented breeding area for loggerhead turtles in the Mediterranean (Margaritoulis, 2005), with a mean of 1,200 nests per year. At this site marine turtle mating activity peaks in mid April (Schofield et al., 2010), with females nesting from late May until August. Individual females nest three times per season, after which they return to distant foraging grounds (Zbinden et al., 2008). The breeding area encompasses six beaches (Marathonisi,
Kalamaki, Crystal, Sekania, Daphni and Gerakas), covering a total length of $6.3 \mathrm{~km}$ of available nesting habitat. The beaches support varying numbers of nests and differ in environmental conditions and human use (Table 1; Margaritoulis, 2005). Because of the island's location in the Mediterranean, tidal effect is minimal. In general, storms rarely occur after May or before September, when over $80 \%$ of nests hatch (Margaritoulis, 2005), so the beaches are not altered by wave action during this period. Visitor access is prohibited on one beach (Sekania) and is regulated on the other five beaches (for protocols see Table 2). Permanent beach furniture is permitted on three of the beaches, with the numbers and location being specified by the Park at the start of each season (Table 2).

\section{Methods}

A global positioning system (GPS) with an accuracy of $<3 \mathrm{~m}$ was used to record the position of the following parameters at $2 \mathrm{~m}$ intervals: vegetation line (once per year in May), calm sea line (weekly in May-October), wet sand line (i.e. highest tide line, weekly in May-October), storm line (every event where the sea encroached a distance of $>5 \mathrm{~m}$ up the beach). This information was transferred to digital maps. In 200778 transects traversing the beaches (i.e. from calm sea level to the beach vegetation line, or cliff face or wall) were delineated (using a GPS) at $50 \mathrm{~m}$ intervals along all nesting beaches except Kalamaki, on which transects were delineated at $100 \mathrm{~m}$ intervals because of the relatively greater length $(3 \mathrm{~km})$ of this beach. In 2008-2009 the same transect lines were reassessed for inter-season comparisons. Beach elevation was measured at $3 \mathrm{~m}$ intervals along each transect, using a digital theodolite, in May of all 3 years, and repeated in August 2007 to determine beach stability during the summer, with a mean difference across measurements of $0.034 \pm \mathrm{SD} 0.012 \mathrm{~m}$, indicating that the beaches were stable.

Laying and hatching were monitored during MayOctober of 2007, 2008 and 2009 through nightly patrols and daily dawn beach surveys. The position of all emergences from the sea and resultant nests were recorded, using a GPS, in relation to markers at 20-50 $\mathrm{m}$ intervals along the back of the beach. In all 3 years the minimum number of nests was confirmed by at least one of the following methods: (1) locating eggs for relocation and/or caging the morning after egg laying, (2) matching laid and hatched nest locations, and (3) hatched nests not recorded at egg laying. For nests relocated from their natural locations, the original and new locations were recorded, with the original being used for the purposes of this study. For each nest the distance to the sea was measured at egg laying and hatching. We used a theodolite to measure the elevation of $70 \%$ of nests during August of each year. We also measured the elevation above sea level of a sample of 
TABLE 1 Marine turtle nesting and beach parameters at the six nesting beaches monitored on Zakynthos (Fig. 1) during 2007-2009. The beach width and elevation are measured between the calm sea level and the vegetation line. Means are \pm SD.

\begin{tabular}{|c|c|c|c|c|c|c|c|c|c|c|c|}
\hline \multirow[b]{2}{*}{$\begin{array}{l}\text { Year (by } \\
\text { beach) }\end{array}$} & \multicolumn{5}{|c|}{ Marine turtle nesting parameters } & \multicolumn{6}{|c|}{ Beach parameters } \\
\hline & $\begin{array}{l}\text { Total no. of } \\
\text { emergences }\end{array}$ & $\begin{array}{l}\text { Total no. } \\
\text { of nests }\end{array}$ & $\begin{array}{l}\text { Nest } \\
\text { density } \\
\mathrm{km}^{-1}\end{array}$ & $\begin{array}{l}\text { Mean nest } \\
\text { distance } \\
\text { from } \\
\text { shore }(m)\end{array}$ & $\begin{array}{l}\text { Mean nest } \\
\text { elevation } \\
(\mathrm{m})\end{array}$ & $\begin{array}{l}\text { No. of } \\
\text { transects }\end{array}$ & $\begin{array}{l}\text { Orientation } \\
\left({ }^{\circ}\right)\end{array}$ & $\begin{array}{l}\text { Length } \\
\text { (m) }\end{array}$ & $\begin{array}{l}\text { Width } \\
(\mathrm{m})\end{array}$ & $\begin{array}{l}\text { Elevation } \\
(\mathrm{m})\end{array}$ & $\begin{array}{l}\text { Slope } \\
\text { angle }\left({ }^{\circ}\right)\end{array}$ \\
\hline \multicolumn{12}{|l|}{ Gerakas } \\
\hline 2007 & 249 & 92 & 158 & $16.0 \pm 6.4$ & $0.99 \pm 0.21$ & 10 & 230 & 594.6 & $26.5 \pm 7.5$ & $1.47 \pm 0.51$ & $14.7 \pm 2.4$ \\
\hline 2008 & 184 & 45 & 75 & $22.2 \pm 4.6$ & $0.94 \pm 0.26$ & 10 & 230 & 604.2 & $31.7 \pm 6.9$ & $1.47 \pm 0.46$ & $15 \pm 3.1$ \\
\hline 2009 & 273 & 91 & 152 & $14.8 \pm 5.0$ & $1.1 \pm 0.32$ & 10 & 230 & 574.5 & $24.8 \pm 7.7$ & $1.78 \pm 0.50$ & $22.3 \pm 6.7$ \\
\hline \multicolumn{12}{|l|}{ Daphni } \\
\hline 2007 & 1,169 & 143 & 206 & $12.3 \pm 2.9$ & $1.01 \pm 0.35$ & 12 & 180 & $1,015.3$ & $17.7 \pm 6.5$ & $1.34 \pm 0.26$ & $23.9 \pm 3.9$ \\
\hline 2008 & 1,113 & 137 & 196 & $12.5 \pm 2.5$ & $0.91 \pm 0.14$ & 12 & 180 & $1,027.9$ & $20.0 \pm 6.9$ & $1.77 \pm 0.53$ & $22.67 \pm 3.5$ \\
\hline 2009 & 1,207 & 65 & 93 & $11.9 \pm 3.9$ & $1.1 \pm 0.28$ & 12 & 180 & 972.3 & $15.6 \pm 5.1$ & $1.48 \pm 0.58$ & $25.6 \pm 7.5$ \\
\hline \multicolumn{12}{|l|}{ Sekania } \\
\hline 2007 & 1,485 & 537 & 806 & $17.0 \pm 4.8$ & $0.91 \pm 0.19$ & 12 & 200 & 800.6 & $23.4 \pm 8.5$ & $1.14 \pm 0.22$ & $16.9 \pm 6.5$ \\
\hline 2008 & 1,409 & 481 & 740 & $16.7 \pm 5.9$ & $1.07 \pm 0.17$ & 12 & 200 & 742.7 & $23.7 \pm 7.3$ & $1.37 \pm 0.39$ & $17.9 \pm 6.9$ \\
\hline 2009 & 1,207 & 417 & 642 & $16.2 \pm 4.6$ & $1.17 \pm 0.26$ & 12 & 200 & 782.2 & $24.0 \pm 7.5$ & $1.38 \pm 0.39$ & $17.1 \pm 5.7$ \\
\hline \multicolumn{12}{|l|}{ Crystal } \\
\hline 2007 & 390 & 102 & 180 & $16.1 \pm 2.5$ & $0.94 \pm 0.14$ & 10 & 170 & 578.2 & $20.7 \pm 7.4$ & $1.13 \pm 0.16$ & $16.8 \pm 4.7$ \\
\hline 2008 & 404 & 94 & 163 & $15.8 \pm 2.7$ & $1.00 \pm 0.19$ & 10 & 170 & 613.5 & $22.6 \pm 6.4$ & $1.45 \pm 0.24$ & $17.2 \pm 3.8$ \\
\hline 2009 & 229 & 78 & 135 & $13.1 \pm 2.3$ & $1.01 \pm 0.09$ & 10 & 170 & 562.7 & $21.7 \pm 6.1$ & $1.51 \pm 0.27$ & $17.1 \pm 3.0$ \\
\hline \multicolumn{12}{|c|}{ Kalamaki } \\
\hline 2007 & 319 & 137 & 48 & $24.4 \pm 7.7$ & $0.94 \pm 0.19$ & 28 & 160 & $2,789.1$ & $31.9 \pm 14.3$ & $1.52 \pm 0.37$ & $12.3 \pm 3.5$ \\
\hline 2008 & 437 & 138 & 48 & $23.4 \pm 7.3$ & $1.25 \pm 0.32$ & 28 & 160 & $3,065.2$ & $32.3 \pm 11.8$ & $1.59 \pm 0.37$ & $10.6 \pm 3.9$ \\
\hline 2009 & 642 & 156 & 55 & $24.3 \pm 7.1$ & $1.08 \pm 0.34$ & 28 & 160 & $2,615.9$ & $30.3 \pm 12.6$ & $1.55 \pm 0.32$ & $13.5 \pm 2.9$ \\
\hline \multicolumn{12}{|c|}{ Marathonisi } \\
\hline 2007 & 242 & 102 & 281 & $23.5 \pm 2.8$ & $1.04 \pm 0.17$ & 6 & 0 & 383.3 & $51.0 \pm 16.8$ & $1.40 \pm 0.33$ & $12.7 \pm 9.6$ \\
\hline 2008 & 263 & 99 & 268 & $19.8 \pm 2.7$ & $1.01 \pm 0.22$ & 6 & 0 & 364.8 & $43.2 \pm 18.8$ & $1.26 \pm 0.47$ & $14.7 \pm 10.5$ \\
\hline 2009 & 238 & 50 & 135 & $27.7 \pm 7.2$ & $0.92 \pm 0.15$ & 6 & 0 & 348.9 & $42.7 \pm 15.3$ & $1.29 \pm 0.26$ & $11.0 \pm 7.2$ \\
\hline
\end{tabular}


TABLE 2 Marine turtle and anthropogenic parameters at the six nesting beaches on Zakynthos (Fig. 1). Only data from 1 June to 31 August, between 10.00 and 19.00, were used. Hourly limits were not exceeded in the data recorded in May, September or October. Protected nests indicate caged and/or relocated nests. Numbers in parentheses indicate the number of nests caged.

\begin{tabular}{|c|c|c|c|c|c|c|c|c|c|}
\hline \multirow[b]{3}{*}{$\begin{array}{l}\text { Year (by } \\
\text { beach) }\end{array}$} & \multicolumn{2}{|c|}{ Marine turtle parameters } & \multicolumn{7}{|c|}{ Anthropogenic parameters } \\
\hline & \multirow{2}{*}{$\begin{array}{l}\text { No. of } \\
\text { protected } \\
\text { nests in } \\
\text { permanent } \\
\text { furniture zone }\end{array}$} & \multirow[b]{2}{*}{$\begin{array}{l}\text { No. of nests } \\
\text { overlapping } \\
\text { area used } \\
\text { by visitors }\end{array}$} & \multicolumn{3}{|c|}{ No. of visitors per hour } & \multicolumn{2}{|c|}{$\underline{B e a c h}$ furniture } & \multirow[b]{2}{*}{$\begin{array}{l}\text { Distance } \\
\text { to } \operatorname{sea}^{2}(\mathrm{~m})\end{array}$} & \multirow[b]{2}{*}{$\begin{array}{l}\text { Elevation }^{3} \\
(\mathrm{~m})\end{array}$} \\
\hline & & & Legal limit & Mean & Max. & $\begin{array}{l}\text { Legal } \\
\text { no. of } \\
\text { umbrellas }\end{array}$ & $\begin{array}{l}\text { Length } \\
\text { across } \\
\text { beach }^{1} \\
(\mathrm{~m})\end{array}$ & & \\
\hline \multicolumn{10}{|l|}{ Gerakas } \\
\hline 2007 & 4 & $14(7)$ & 350 & 199 & 956 & 60 & 140 & $7-17$ & $0.5-0.9$ \\
\hline 2008 & 6 & $13(12)$ & & & 194 & 985 & & $7-18$ & $0.5-0.7$ \\
\hline 2009 & 13 & $20(18)$ & & & 227 & 896 & & $9-16$ & $0.6-0.9$ \\
\hline \multicolumn{10}{|l|}{ Daphni } \\
\hline 2007 & & $22(22)$ & 100 & 69 & 415 & 0 & 0 & & \\
\hline 2008 & & $13(13)$ & & & 59 & 380 & & & \\
\hline 2009 & & $8(8)$ & & & 55 & 401 & & & \\
\hline \multicolumn{10}{|l|}{ Sekania } \\
\hline 2007 & & & Access & & & 0 & 0 & & \\
\hline 2008 & & & prohibited $^{4}$ & & & & & & \\
\hline \multicolumn{10}{|l|}{2009} \\
\hline \multicolumn{10}{|l|}{ Crystal } \\
\hline 2007 & 4 & $19(16)$ & None & 181 & 380 & 56 & 230 & $9-16$ & $0.5-0.9$ \\
\hline 2008 & 4 & $12(10)$ & & 175 & 612 & & & $9-16$ & $0.4-1.1$ \\
\hline 2009 & 3 & $18(16)$ & & 127 & 508 & & & $9-16$ & $0.5-1.2$ \\
\hline \multicolumn{10}{|c|}{ Kalamaki } \\
\hline 2007 & 4 & $17(13)$ & None & 181 & 360 & 206 & 310 & $10-20$ & $0.4-1.0$ \\
\hline 2008 & 0 & $20(13)$ & & & 175 & 612 & & $10-20$ & $0.3-0.9$ \\
\hline 2009 & 1 & $21(15)$ & & & 127 & 508 & & $10-20$ & $0.3-0.9$ \\
\hline \multicolumn{10}{|c|}{ Marathonisi } \\
\hline 2007 & & $7(4)$ & None & 216 & 619 & 0 & 0 & & \\
\hline 2008 & & $9(3)$ & & 211 & 501 & & & & \\
\hline 2009 & & $5(2)$ & & 223 & 739 & & & & \\
\hline
\end{tabular}

${ }^{1}$ Length of beach covered by beach furniture

${ }^{2}$ Range of the distance of beach furniture from the sea

${ }^{3}$ Range of the elevation of beach furniture above sea level

${ }^{4} \mathrm{No}$ data as the number of visitors to this beach is negligible ( $<100$ visitors over the entire season)

20 caged nests at egg laying and hatching, to confirm that measurements were similar between June and August (mean difference $0.004 \pm \mathrm{SD} 0.001 \mathrm{~m}$ ). The spatial distribution of all nesting (turtle tracks that resulted in nests) and non-nesting (turtle tracks that did not result in nests) emergences from the sea onto the shore of the six nesting beaches was evaluated for each $100 \mathrm{~m}$ section, using methodology adapted from Weishampel et al., (2003). We used Moran's I (Griffith, 1988) to determine if there was a significant correlation of the observed nesting and nonnesting emergences at one location with emergences at other sampling locations.

The locations of all anthropogenic features were recorded with a GPS. The area designated for permanent beach umbrellas was mapped in May and rechecked weekly. In addition, the distance from the sea and elevation of the lowest and highest items of furniture were measured.
The number of nests caged and left in situ or relocated out of these areas was recorded in each season. The area of beach used by visitors at the busiest hour and day of the week was recorded (weekends during 14.00-16.00; calculated from 2007-2009 National Marine Park of Zakynthos guard data sets). The location of the highest point of the beach used by visitors was recorded, with a GPS, at $2 \mathrm{~m}$ intervals on all beaches (except Sekania).

The overlap in the distribution of nests with the area used by people was determined by measuring the number of nests within areas of recorded tourist use by overlaying the GPS data for the two data sets using ArcMap v. 9.1 (ERSI, Redlands, USA). We used beach slope data to calculate the probability of nests occurring in designated beach furniture zones.

Descriptive statistics, linear regression and the coefficient of variation were used to evaluate statistical trends within 
and between the data sets. Statistical significance was at $\mathrm{P}<0.05$.

\section{Results}

\section{Environmental parameters}

The beaches of Sekania, Daphni and Marathonisi had the most stable elevation across the 3 years of study (coefficient of variation, CV, of $0.8,0.8$ and 0.9 in 2007, 2008 and 2009, respectively), followed by Crystal, Gerakas and Kalamaki (CV 0.13, 0.16 and 0.17 , respectively). Beach slope varied by a mean of $3.26 \pm \mathrm{SD} 3.19^{\circ}$ between seasons. Slope and distance to sea were negatively correlated $\left(F_{1,204}=199, r^{2}=0.7\right.$, $\mathrm{P}<0.0001)$; i.e. beaches with narrower widths had a steeper incline and vice versa. Daphni had the narrowest width and steepest incline and Kalamaki had the greatest width and shallowest incline (Fig. 2a,b; Table 1).

Although beach width varied across the 78 transects (mean $27.4 \pm \mathrm{SD} 12.3 \mathrm{~m}$, range 7-68 m, CV 0.45; Fig, 2a, Table 1) it remained relatively stable within each beach (CV 0.03-0.09) across years (CV 0.07; Fig. 2a, Table 1). The elevation of the transects was more uniform (mean: $1.45 \pm \mathrm{SD} 0.4 \mathrm{~m}, \mathrm{CV} 0.28$, range $0.73-2.88 \mathrm{~m}$ ) across all beaches. However, the angle of the slope was variable (mean 16.2 \pm SD 6.5, range $3-44^{\circ}$; Fig. 2 b, Table 1), being generally consistent across the beaches in all years (CV 0.07$)$ but with a noticeable interannual variation for individual beaches.

\section{Nesting parameters}

In total 3,854, 4,015 and 3,154 turtle emergences from the sea were recorded on the six beaches in 2007, 2008 and 2009, respectively, of which 1,113, 994 and 858, respectively, were nests. On average $91.6 \%$ of nests were below the vegetation line (2007: 92.7\%; 2008: 92.4\%; 2009: 89.3\%), and the remainder were above the vegetation line. In all 3 years the majority of turtle emergences occurred at Sekania and Daphni; however, although Sekania had the majority of nests in all 3 years, Daphni did not follow a similar trend. Hence, sites selected for emergence may not necessarily be viable for nesting. Overall, Sekania and Marathonisi supported the largest nesting densities (number of nests per $\mathrm{km}$ of nesting beach). In addition, these two beaches had the most stable spatial distribution of emergences across years (i.e. emergences occurred at similar locations in different seasons; CV 0.03 and 0.07 , respectively) followed by Gerakas, Kalamaki, Crystal and Daphni (CV 0.09, 0.1, 0.2 and 0.33, respectively; Table 1). Sekania and Daphni had the lowest variability in the spatial distribution of nests (CV 0.12 and 0.20 , respectively), followed by Gerakas, Kalamaki, Crystal and Marathonisi (CV 0.36, 0.54, 0.62 and 0.74 , respectively).
The distribution of emergences was strongly correlated with beach slope angle $\left(\mathrm{F}_{1,200}=121, \mathrm{r}^{2}=0.63, \mathrm{P}<0.0001\right)$, although the correlation between the spatial distribution of nests and beach slope angle was weak $\left(F_{1,200}=9, r^{2}=0.21\right.$, $\mathrm{P}=$ 0.002). There were weak negative correlations for beach width and the spatial distribution of emergences $\left(\mathrm{F}_{1,200}=48, \mathrm{r}^{2}=0.40, \mathrm{P}<0.001\right)$ and the spatial distribution of nests $\left(\mathrm{F}_{1,200}=15 ; \mathrm{r}^{2}=0.27 ; \mathrm{P}=0.001\right)$.

The spatial distribution of all turtle emergences (both nesting and non-nesting) and the resultant nests across years were relatively consistent along the total $6.3 \mathrm{~km}$ length of nesting beach (CV 0.04 and o.1, respectively; Figs. 2c,d, 3a); however, there was noticeable interannual variation for individual beaches (CV $0.03-0.33$ and $0.12-0.73$, respectively). Track density and the number of resultant nests per $100 \mathrm{~m}$ section were correlated (Fig. 3a, trendline 1: $\left.F_{1,200}=105, \quad r^{2}=0.6, \quad \mathrm{P}<0.0001\right) . \quad$ This correlation strengthened when excluding Daphni (Fig. 3a, trendline 2: $\left.F_{1,170}=172, r^{2}=0.72, \mathrm{P}<0.0001\right)$ or Sekania and Daphni (Fig. 3a, trendline 3: $F_{1,146}=493, r^{2}=0.88, \mathrm{P}<0.0001$ ), indicating that parameters other than emergence site may influence nest placement.

\section{Nesting and environmental parameters}

Overall, mean nest elevation was $1.08 \pm \mathrm{SD} 0.4 \mathrm{~m}$ (CV 0.37, range $0.3-2.6$ ) and mean nest distance from the sea was $17 \pm$ SD $6.99 \mathrm{~m}$ (CV 0.41, range 2-52.6). There was no temporal variation in nest elevation across the nesting period $\left(F_{1,1471}=0.47, r^{2}=0.0001, \mathrm{P}=0.49\right)$. Nest elevation and distance to sea were positively correlated for a sample of nests $\left(\mathrm{n}=1,472\right.$ nests across all seasons; $F_{1,1471}=507$, $\left.r^{2}=0.26, \mathrm{P}<0.0001\right)$. We used the variability in beach slope along transects to evaluate whether turtles nest at the same elevation but travel further from the sea or nest at the same distance from the sea but at a different elevation. We found that with increasing beach slope there was a decline in the distance travelled to the nest $\left(F_{1,182}=121, r^{2}=0.47\right.$, $\mathrm{P}<0.0001$; Fig. $3 \mathrm{~b}$ ). In contrast, nest elevation remained consistent at just over $1 \mathrm{~m}$ above sea level across the entire range of beach slope angles (i.e. $0-35^{\circ}, F_{1,182}=0.46$, $r^{2}=0.003, \mathrm{P}<0.0001$; Fig. $\left.3 \mathrm{~b}\right)$. Hence, beach slope is the more reliable indicator of where nests are likely to be placed on a beach in relation to sea level. Using the mean \pm SD nest elevation data, the optimal width of the beach area available for nesting was 3.5 5.5, 7.5, 8.5, 10 and $14.5 \mathrm{~m}$ on Crystal, Kalamaki, Daphni, Sekania, Gerakas and Marathonisi, respectively.

During the nesting season (May-September) wave action occurred on the beaches when wind speeds exceeded $22 \mathrm{~km} \mathrm{~h}^{-1}$, which was determined by seven major beachwashing events, recorded using GPS units, between 2007 and 2009. The mean elevation of the calm sea wet sand line 

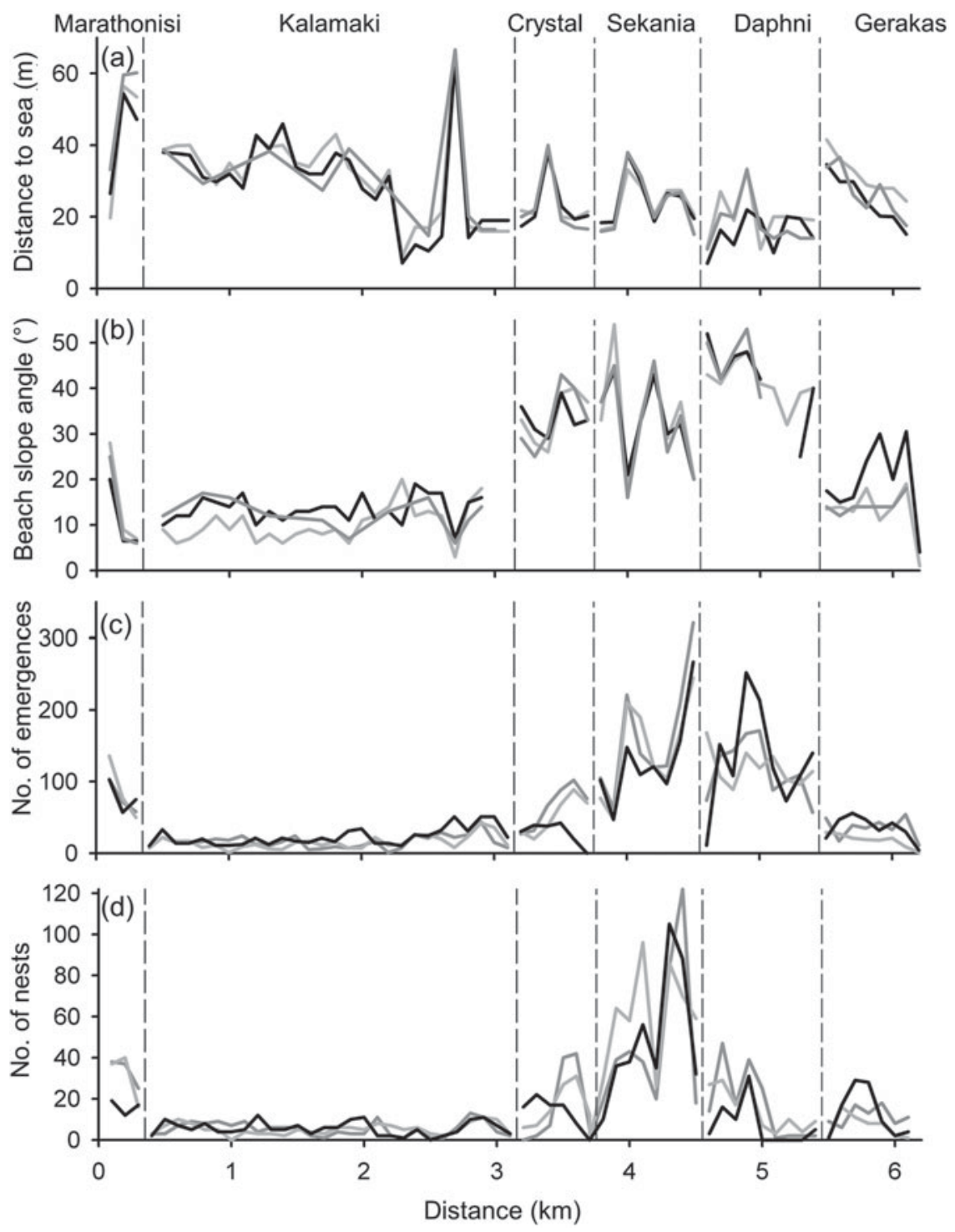

FIG. 2 Variation in (a) beach width, (b) beach slope, (c) number of marine turtle emergences, and (d) number of marine turtle nests on the 78 transects along the total $6.3 \mathrm{~km}$ of the six loggerhead turtle nesting beaches in 2007 (dark grey line), 2008 (light grey line) and 2009 (black line). The $\mathrm{x}$-axis represents the total $6.3 \mathrm{~km}$ length of nesting beach.

(i.e. high tide) was $0.32 \pm \mathrm{SD} 0.17 \mathrm{~m}$ above sea level, whereas that of summer storms (wind speeds $>22 \mathrm{~km} \mathrm{~h}^{-1}$ ) was $0.55 \pm \mathrm{SD} 0.065 \mathrm{~m}$ above sea level. We found that $3-8 \%$ of nests fell within the mean summer storm line, with $>80 \%$ nests having hatched before September storms in all years. The worst case scenario would be a summer storm $>22 \mathrm{~km} \mathrm{~h}^{-1}$ from late July to early August (i.e. during the peak period of incubation for this site), whereby all nests below $0.79 \mathrm{~m}$ elevation (i.e. maximum recorded storm line) would be washed (but still hatch) or inundated, which would account for $26.7 \%$ of all nests in a given season.

\section{Nesting and anthropogenic parameters}

In total $>300,000$ visitors frequented the nesting beaches open to the public (i.e. excluding Sekania) during June-August of each year. On average, there were 35-227 visitors per hour (Table 2), swelling to $170-985$ visitors per hour at peak times (14.00-16.00, Saturday-Sunday, August).

Although only $7 \%$ of nests overlapped with beach visitor use each year (i.e. 79, 67 and 72 nests in 2007, 2008 and 2009, respectively; Fig. $4 \mathrm{a}-\mathrm{f}$ ), there was the potential for this figure to reach $36 \%$ (Fig. 5a). This is because legal beach furniture zones (Table 2) are up to $20 \mathrm{~m}$ from the sea, and elevation above sea level is up to $1.3 \mathrm{~m}$. Of the nests that overlapped with visitor area use $76-81 \%$ nests were caged and hence received additional protection (Table 2 ).

Because nests are more likely to be placed closer to shore on steeper slopes, the risk of overlap with and damage by tourism is increased. Therefore, we evaluated whether the existing overlap could be further reduced by focusing annual conservation effort (i.e. further reducing human use) on beach sections with the steepest inclines (Fig. 5b). For example, if access to all sections of beach (excluding 

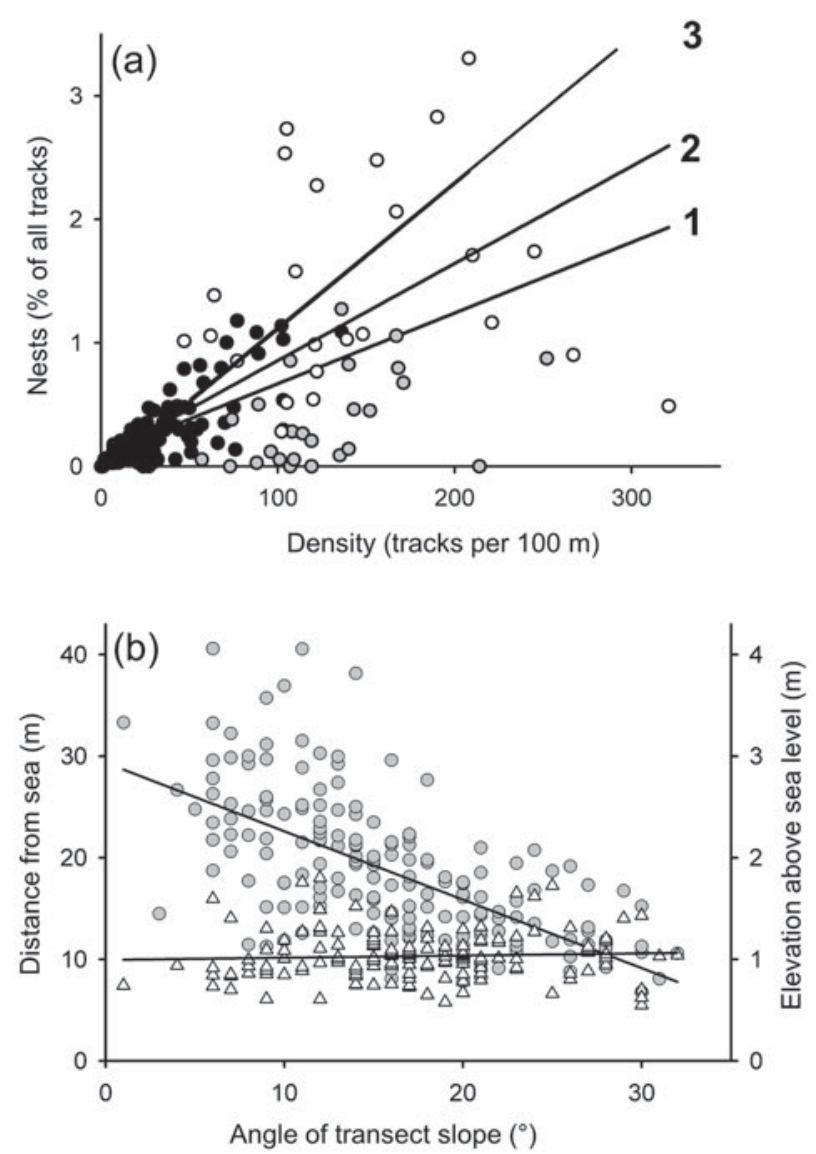

Fig. 3 (a) Correlation between resultant nests (as \% of total tracks per season) and track density (per $100 \mathrm{~m}$ ). Line 1 is the correlation for all beaches $\left(F_{1,200}=105, r^{2}=0.6, \mathrm{P}<0.0001\right)$; line 2 is for all beaches excluding Daphni (grey circles; $\left.F_{1,170}=172, r^{2}=0.72, \mathrm{P}<0.0001\right)$; line 3 is for all beaches excluding Sekania and Daphni (white and grey circles respectively; $F_{1,146}=493, r^{2}=0.88, \mathrm{P}<0.0001$ ). (b) Nest placement parameters (distance and elevation) with respect to the slope angle of all transects $(n=78)$ across all six nesting beaches in 2007-2009. Distance to sea (circles) was negatively correlated with increasing beach slope angle $\left(r^{2}=0.47\right.$, $\mathrm{P}<0.0001$ ), whereas elevation above sea level (triangles) was consistent for all slope types $\left(r^{2}=0.003, \mathrm{P}<0.0001\right)$.

Sekania) with slopes $>22^{\circ}$ was restricted (i.e. by limiting visitor use to passage along the sea line only), $50 \%$ of nests would be completely protected at the cost of $1,100 \mathrm{~m}$ total beach length (i.e. $20 \%$ ) currently open to the general public. However, the steepest sections change annually across the nesting area. For example, in 2007-2008 just one $100 \mathrm{~m}$ section at Gerakas had a slope $>20^{\circ}$, whereas in 2009 there were six viable sections. The closure of $600 \mathrm{~m}$ of this $1,000 \mathrm{~m}$ beach would not be practical because of its high visitor load (Table 2). Hence, following identification of the steepest slopes each year, the management agency needs to develop additional criteria to select core sections for additional protection by taking into account actual beach length and visitor use (and hence impact on both nests and tourists).

\section{Discussion}

Our results show that the nesting beaches of Zakynthos exhibit a broad spatial range in slope and width characteristics. Annual variation in beach slope characteristics probably results from exposure to strong wind and wave action (e.g. Kamel \& Mrosovsky, 2004; Fuentes et al., 2010) during the non-nesting period (October-April), causing the accretion and erosion of sand and consequently leading to changes in the distribution of emergences of turtles from the sea and resultant nests. With respect to nesting beach selection, our results support that of Mazaris et al., (2006), who found a weak correlation between nest distribution and beach slope. However, we recorded a strong correlation in the distribution of emergence locations with steep beach slopes (and in general narrower beach widths). We suggest that the difference between distributions of emergences from the sea and resultant nest distributions is because additional parameters influence the outcome of nesting (Godley et al., 2001), including the presence of stones, clay and marine debris, and sand characteristics (e.g. Mortimer, 1990; Weishampel et al., 2003). With respect to nest-site selection, we recorded mean nest elevations of $1 \mathrm{~m}$ above sea level, strongly corroborating previous studies (Johannes \& Rimmer, 1984; Horrocks \& Scott, 1991; Wood \& Bjorndal, 2000; Weishampel et al., 2003). Hence, beach slope provides a reliable way to identify potential emergence and nest-site positioning for annual adjustment of the management of anthropogenic activities (Hansen et al., 2009).

Our study shows that turtles must respond to annual changes in beach slope characteristics to locate suitable environmental conditions for nesting (e.g. Kolbe \& Janzen, 2002; Tucker, 2010). In theory, repeated use of the same habitat may improve fitness as it reduces the cost of search effort (e.g. Encalada et al., 1998). Hence, fidelity is predicted to arise in areas of high stability and associated high nesting density (Switzer, 1993). For example, the high nesting densities recorded in our study at Sekania may be explained by high fidelity of the adult population because of the stable characteristics of the beach, possibly combined with the effect of natal homing of offspring (Encalada et al., 1998; Weishampel et al., 2003). In comparison, the large number of failed nesting emergences recorded on the neighbouring beach of Daphni indicates that turtles are not necessarily selecting the most suitable sites to emerge. Hence, fidelity to beach or nest sites may be broad (rather than precise), corroborated by the $70 \%$ fidelity to beaches previously recorded for this population (Katselidis et al., 2004). However, this strategy requires the expenditure of larger amounts of energy in exploratory emergences, which may reduce the total number of possible nests (and hence fitness) by an individual in a given season. In general, as habitat quality affects individual and offspring fitness, prospecting and using more than one habitat may present a more 
CRYSTAL

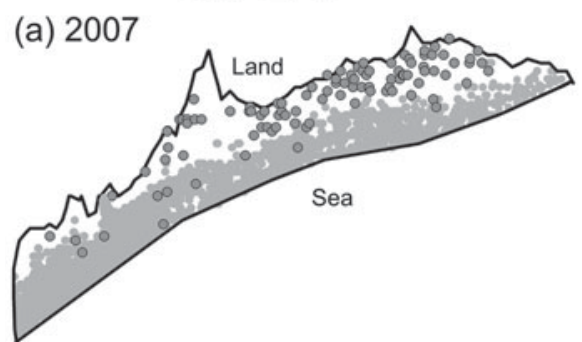

(b) 2008

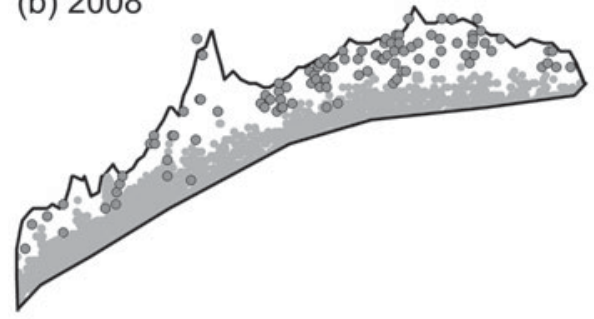

(d) 2007

MARATHONISI

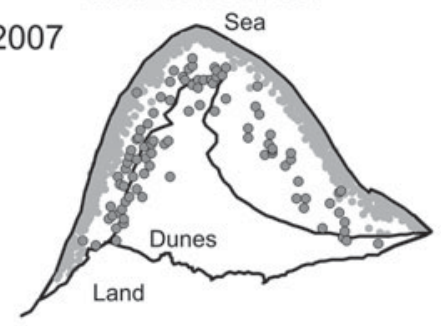

(e) 2008

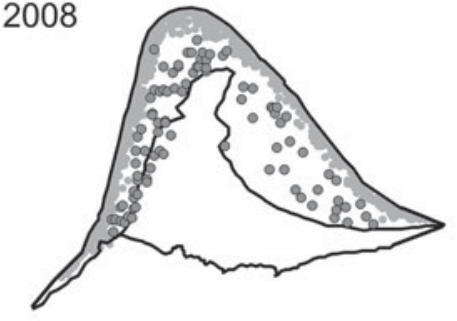

(c) 2009

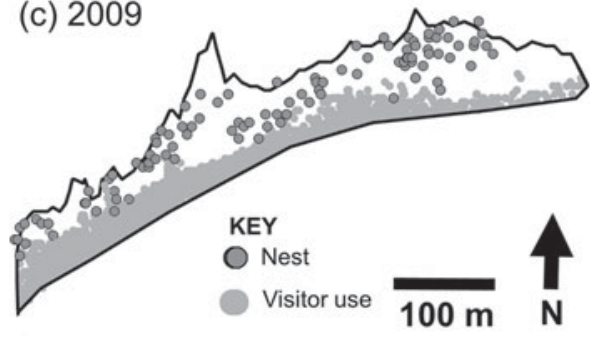

(f) 2009

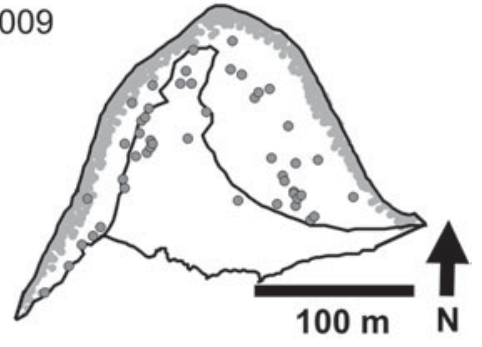

FIG. 4 Example of interseasonal variation in nest distribution versus visitor area use at the nesting beaches of Crystal $(\mathrm{a}-\mathrm{c})$ and Marathonisi (d-f) in 2007, 2008 and 2009. evolutionary stable strategy (e.g. Switzer, 1993; Kolbe \& Janzen, 2002; Tucker, 2010), particularly when information on offspring success rates is not available to the parent, as is the case for marine turtles.

We found that $90 \%$ of nests occurred below the vegetation line and $90 \%$ of nests occurred above the mean summer storm inundation line of waves. In many species that nest adjacent to water bodies there is a risk of egg loss from inundation by seasonally rising water levels or land erosion by storms (e.g. shorebirds, Frederic, 1987; marine turtles, Pfaller et al., 2008), penetration by roots (e.g. marine turtles, Wood \& Bjorndal, 2000; crocodiles, Leslie \& Spotila, 2001), and excessive moisture, salinity, desiccation, or increased risk of predation of eggs or offspring (e.g. marine turtles, Wood \& Bjorndal, 2000; terrapins, Spencer \& Thompson, 2003). Trade-offs often occur; for example, when predation pressure is strong individuals may locate nests closer to shore in less suitable habitats (e.g. Spencer \& Thompson, 2003). Alternatively, some species preferentially select sites with a risk of predation because of the high suitability of the habitat (e.g. Wootton, 1992). On Zakynthos predation risk is minimal (Margaritoulis, 2005) and we found that $<10 \%$ of nests are at risk of inundation from summer storms, with only nests laid late in the season (i.e. after mid July) being at risk of inundation from September storms, corroborating the findings of Pike (2007). Based on our evaluation the predicted worst case scenario inundation level was $26.7 \%$ of nests, which closely matched the $32 \%$ recorded by Margaritoulis (2005) for the 2002 season during which strong southerly winds occurred from mid July onwards. However, such conditions have only been recorded twice in a 27-year period (Margaritoulis, 2005), and nests of other breeding populations are subject to as much as a $60 \%$ risk of inundation (Eckert, 1987; Pike, 2007). On Zakynthos mean summer storm inundation risk and vegetation may regulate nest placement to $1 \mathrm{~m}$ elevation above sea level, along with other drivers such as moisture levels, salinity and pH (Godley et al., 2001; Weishampel et al., 2003), or even the highest spring tide line (Kamel \& Mrosovsky, 2004). In comparison, the positioning of nests by marine turtle populations elsewhere may be driven by different co-varying forces (Storch \& Frynta, 1999; Pfaller et al., 2008), resulting in the marked variation recorded in research on nest-site selection (e.g. Eckert, 1987; Hays et al., 1995; Weishampel et al., 2003).

Our study shows that effective beach protection requires information about the locations of all emergences and nests, as both aspects represent different habitat selection criteria at different phases of the nesting process. Because of the changing distribution of emergence and nest locations in response to changing environmental conditions each year the full extent of all nesting beaches should be viewed 

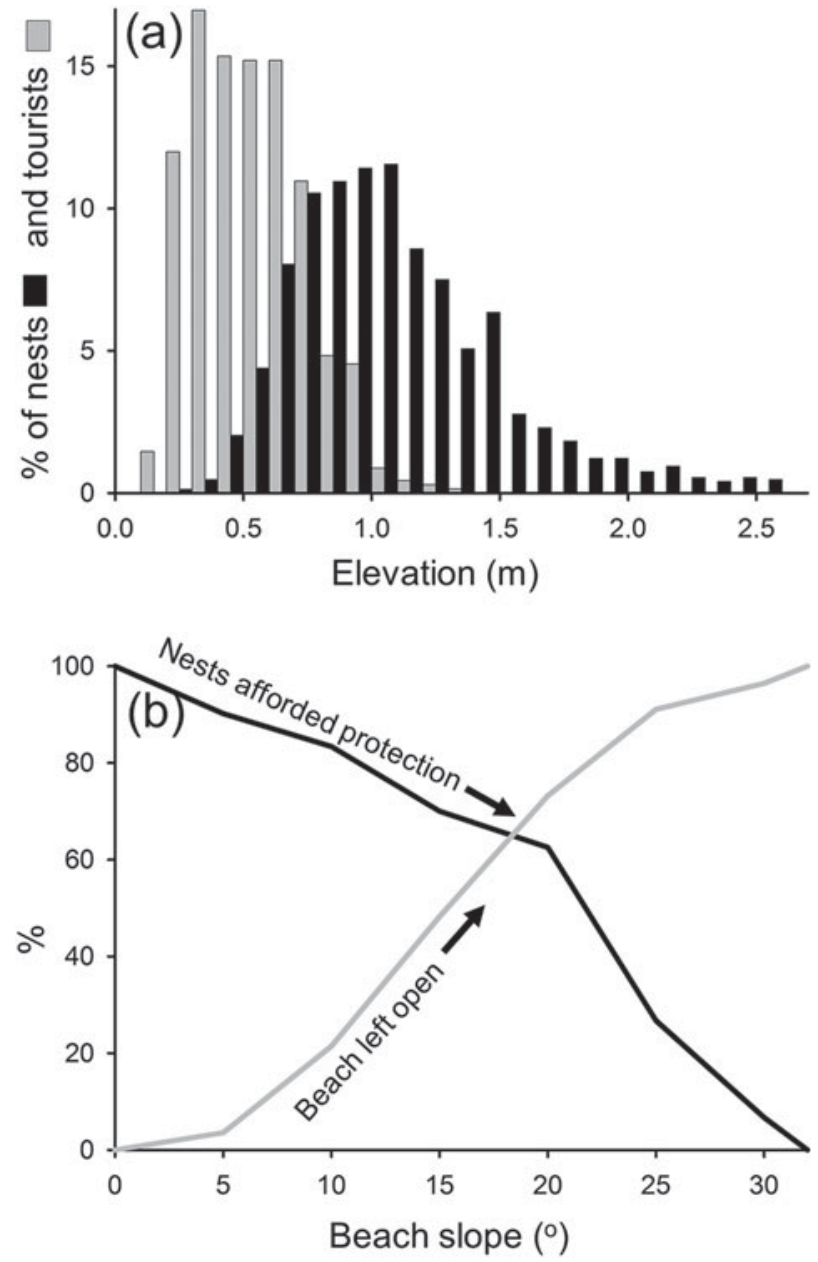

FIG. 5 (a) Percentage of nests (black bars; $\mathrm{n}=1,472$ ) and visitor area use (grey bars; $\mathrm{n}=2,232$ ) in relation to beach elevation across the 3-year survey period. (b) The percentage of nests that could potentially be afforded protection (black line) and the percentage of beach left open to the general public (grey line) with respect to beach slope parameters.

as potentially viable nesting habitat, with the sections receiving the most protection being adjusted each year (Grantham et al., 2010). For instance, the delineation of static zones based on nesting and/or emergence data from previous years may not reflect the conditions of a particular year. Beach slope characteristics could be used as a practical and effective tool to predict the key zones used by turtles each year, and thus adjustment of the permitted area used for tourism (visitors and business operators alike; Grantham et al., 2010; Wintle et al., 2010).

Beach use is two dimensional, with both beach width, (i.e. sea to vegetation line) and beach length requiring consideration. Under existing management protocols visitors use the entire beach length but use of the width is restricted. Although the overlap between visitors and nests was only $7 \%$, this could potentially reach $40 \%$ because of legal beach furniture covering a greater width of the beach. Beach use by people should therefore be limited to areas of lower elevation. On steeper sections elevation is higher closer to the sea, further increasing the risk of tourist use overlapping with nests. This problem could be resolved by closing steeper sections of beach, only allowing pedestrian visitors to pass these sections along the shoreline, similar to beach management for ground nesting birds such as oyster catchers and dotterels (James, 2000). Hence, the characteristics of beach slope in a given year could be used to prioritize the most important sites for protection before the onset of the nesting and tourist season (i.e. in May). However, alternative locations for use by displaced tourists should also be provided, such as allowing larger vertical area use in beach sections with shallower beach slopes. In addition, the impact of beach furniture on nests requires quantification.

Annual measurements of beach slope could also contribute towards (1) calculating changes in nest inundation risk, and hence relocation protocols (Kamel \& Mrosovsky, 2004; Pike, 2007; Pfaller et al., 2008), (2) interpreting the impact of different wind strengths and directions on the morphology of nesting beaches, to forecast future beach structures and/or identify alternative suitable habitats (Hulme, 2005; Fuentes et al., 2010), and (3) modelling how this population may adapt to altered environments as a result of climate change or changing anthropogenic pressure (Weishampel et al., 2003; Hansen et al., 2009; Mazaris et al., 2009). Climate change is likely to lead to more hatchlings because of temperature-dependent sex determination (Hays et al., 2010); hence future work should incorporate nest quality (i.e. hatchling success and/or sex ratio) when assessing how to minimize overlap of turtle nests with beach furniture.

Overall, our study shows that loggerhead turtles have the capacity to respond to environmental variables and nest in habitats that suit their requirements; i.e. preferably on beaches with steep inclines and at an elevation of $1 \mathrm{~m}$ above sea level. In turn, the management of such annually dynamic systems must exhibit flexibility. Hence, by identifying the key environmental parameters that drive nest site selection annual changes in these parameters could be monitored and management protocols for the beaches adjusted. In conclusion, this study shows the value of evidence-based management as a practical scientific tool to conserve threatened species in dynamic protected areas that are of both environmental and economic importance.

\section{Acknowledgements}

We thank the National Marine Park of Zakynthos Management Agency for permission to conduct this study, and we are grateful for the assistance of National Marine Park of Zakynthos research personnel, National Marine Park of Zakynthos guards and Archelon volunteers. 
We thank Rick Heron for advice on methodological design and equipment, and Graeme C. Hays and two anonymous reviewers for constructive suggestions.

\section{References}

Arianoutsou, M. (1988) Assessing the impacts of human activities on nesting of loggerhead sea-turtles (Caretta Caretta L.) on Zakynthos island, western Greece. Environmental Conservation, $15,327-334$.

Carr, A. \& Ogren, L. (1960) The ecology and migrations of sea turtles 4. Bulletin of the American Museum of Natural History, 121, 1-48.

EcKerT, K.L. (1987) Environmental unpredictability and leatherback sea turtle (Dermochelys coriacea) nest loss. Herpetologica, 43 , 315-323.

EnCalada, S.E., Bjorndal, K.A., Bolten, A.B., Zurita, J.C., Schroeder, B., Possardt, E. et al. (1998) Population structure of loggerhead turtle (Caretta caretta) nesting colonies in the Atlantic and Mediterranean as inferred from mitochondrial DNA control region sequences. Marine Biology, 130, 567-575.

Frederic, P. (1987) Tidally-induced nest failure in a colony of white ibises. The Condor, 89, 413-419.

Fuentes, M.M.P.B., Limpus, C.J. \& Hamann, M. (2010) Vulnerability of sea turtle nesting grounds to climate change. Global Change Biology, 17, 140-143.

Godley, B.J., Broderick, A.C. \& Hays, G.C. (2001) Nesting of green turtles Chelonia mydas at Ascension Island, South Atlantic. Biological Conservation, 97, 151-158.

Grantham, H.S., Bode, M., McDonald-Madden, E., Game, E.T., Knight, A.T. \& Possingham, H.P. (2010) Effective conservation planning requires learning and adaptation. Frontiers in Ecology and the Environment, 8, 431-437.

Griffith, D.A. (1988) Advanced Spatial Statistics: Special Topics in the Exploration of Quantitative Spatial Data Series. Kluwer Academic, Boston, USA.

Hansen, L., Hoffman, J., Drews, C. \& Mielbrecht, E. (2009) Designing climate-smart conservation: guidance and case studies. Conservation Biology, 24, 63-69.

Hays, G.C., Fossette, S., Katselidis, K.A., Schofield, G. \& Gravenor, M.B. (2010) Breeding periodicity for male sea turtles: good news for conservation in the face of climate change. Conservation Biology, 16, 840-853.

Hays, G.C., Mackay, A., Adams, C.R., Mortimer, J.A., Speakman, J.R. \& Boersma, M. (1995) Nest site selection by sea turtles. Journal of the Marine Biological Association, UK, $75,667-674$.

Hooker, S.K., Canadas, A., Hyrenbach, K.D., Corrigan, C., Polovina, J.J. \& Reeves, R.R. (2011) As we see it: how to make protected area networks effective for marine top predators. Endangered Species Research, 13, 203-218.

Horrocks, J.A. \& Sсотт, N.M. (1991) Nest site location and nest success in the hawksbill turtle (Eretmochelys imbricata) in Barbados, West Indies. Marine Ecology Progress Series, 69, 1-8.

Howell, E.A., Kobayashi, D.R., Parker, D.M., Balazs, G.H. \& Polovina, J.J. (2008) TurtleWatch: a tool to aid in the bycatch reduction of loggerhead turtles Caretta caretta in the Hawaii-based pelagic longline fishery. Endangered Species Research, 5, 267-278.

Hulme, P. (2005) Adapting to climate change: is there scope for ecological management in the face of a global threat? Journal of Applied Ecology, 42, 784-794.

Hyrenbach, K.D., Forney, K.A. \& Dayton, P.K. (2000) Marine protected areas and ocean basin management. Aquatic Conservation: Marine and Freshwater Ecosystems, 10, 437-458.
James, R.J. (2000) From beaches to beach environments: linking the ecology, human-use and management of beaches in Australia. Ocean and Coastal Management, 43, 495-514.

Johannes, R.E. \& Rimmer, D.W. (1984) Some distinguishing characteristics of nesting beaches of the green turtle, Chelonia mydas, on North West Cape Peninsula, Western Australia. Marine Biology, 83, 149-154.

Kamel, S.J. \& Mrosovsky, N. (2004) Nest site selection in leatherbacks, Dermochelys coriacea: individual patterns and their consequences. Animal Behaviour, 68, 357-366.

Katselidis, K., Schofield, G. \& Margaritoulis, D. (2004) Loggerhead nest site fixity and intra-seasonal exchange in the rookery of Laganas Bay, Zakynthos, Greece. In Proceedings of the Twenty-First Annual Symposium on Sea Turtle Biology and Conservation (eds M.S. Coyne \& R.D. Clark), p. 368. U.S. Department of Commerce. NOAA Technical Memorandum NMFS-SEFSC-528, Philadelphia, USA.

Kolbe, J.J. \& Janzen, F.J. (2002) Impact of nest-site selection on nest success and nest temperature in natural and disturbed habitats. Ecology, 83, 269-281.

Leslie, A.J. \& S potila, J.R. (2001) Alien plant threatens Nile crocodile (Crocodylus niloticus) breeding in Lake St Lucia, South Africa. Biological Conservation, 98, 347-355.

Margaritoulis, D. (2005) Nesting activity and reproductive output of loggerhead sea turtles, Caretta caretta, over 19 seasons (1984-2002) at Laganas Bay, Zakynthos, Greece: the largest rookery in the Mediterranean. Chelonian Conservation and Biology, 4, 916-929.

Marine Turtle Specialist Group (1996) Caretta caretta. In IUCN Red List of Threatened Species v. 2012.2. Http://www.iucnredlist.org [accessed 8 May 2013].

Mazaris, A.D., Matsinos, G. \& Pantis, J.D. (2009) Evaluating the impacts of coastal squeeze on sea turtle nesting. Ocean and Coastal Management, 52, 139-145.

Mazaris, A.D., Matsinos, Y.G. \& Margaritoulis, D. (2006) Nest site selection of loggerhead sea turtles: the case of the island of Zakynthos, W. Greece. Journal of Experimental Marine Biology and Ecology, 336, 157-162.

Mortimer, J.A. (1990) The influence of beach sand characteristics on the nesting behavior and clutch survival of green turtles (Chelonia mydas). Copeia, 1990, 802-817.

Pearce, J.L., Kirk, D.A., Lane, C.P., Mahr, M.H., Walmsley, J., CASEY, D. et al. (2008) Prioritizing avian conservation areas for the Yellowstone to Yukon Region of North America. Biological Conservation, 141, 908-924.

Pfaller, J.B., Limpus, C.J. \& BJorndal, K.A. (2008) Nest-site selection in individual loggerhead turtles and consequences for doomed-egg relocation. Conservation Biology, 23, 72-80.

PIKE, D.A. (2007) Sea turtle species vary in their susceptibility to tropical cyclones. Oecologia, 153, 471-478.

Pullin, A.S. \& Knight, T.M. (2009) Doing more good than harm -building an evidence-base for conservation and environmental management. Biological Conservation, 142, 931-934.

Schlacher, T.A., Dugan, J., Schoeman, D.S., Lastra, M., Jones, A., SCapini, F. et al. (2007) Sandy beaches at the brink. Diversity and Distributions, 13, 556-560.

Schofield, G., Bishop, C.M., Katselidis, K.A., Dimopoulos, P., Pantis, J.D. \& HaYs, G.C. (2009) Microhabitat selection by sea turtles in a dynamic thermal marine environment. Journal of Animal Ecology, 78, 14-22.

Schofield, G., Hobson, V.J., Lilley, M.K.S., Katselidis, K.A., Bishop, C.M., BRown, P. \& HAYs, G.C. (2010) Inter-annual variability in the home range of breeding turtles: implications for 
current and future conservation management. Biological Conservation, 143, 722-730.

Spencer, R.-J. \& Thompson, M.B. (2003) The significance of predation in nest site selection of turtles: an experimental consideration of macro- and microhabitat preferences. Oikos, 103, 592-600.

Storch, D. \& Frynta, D. (1999) Evolution of habitat selection: stochastic acquisition of cognitive clues? Evolutionary Ecology, 13, 591-600.

Sutherland, W.J., Pullin, A.S., Dolman, P.M. \& Knight, T.M. (2004) The need for evidence-based conservation. Trends in Ecology and Evolution, 19, 305-308.

Switzer, P.V. (1993) Site fidelity in predictable and unpredictable habitats. Evolutionary Ecology, 7, 533-555.

Thompson, P.M., Wilson, B., Grellier, K. \& Hammond, P.S. (2000) Combining power analysis and population viability analysis to compare traditional and precautionary approaches to conservation of coastal cetaceans. Conservation Biology, 14, 1253-1263.

Tucker, A.D. (2010) Nest site fidelity and clutch frequency of loggerhead turtles are better elucidated by satellite telemetry than by nocturnal tagging efforts: implications for stock estimation. Journal of Experimental Marine Biology and Ecology, 383, 48-55.

Weishampel, J.D., Bagley, D.A., Ehrhart, L.M. \& Rodenbeck, B. L. (2003) Spatiotemporal patterns of annual sea turtle nesting behaviors along an east central Florida beach. Biological Conservation, 110, 295-303.

Wintle, B., Runge, M.C. \& BeKessy, S.A. (2010) Allocating monitoring effort in the face of unknown unknowns. Ecology Letters, $13,1325-1337$.
Wood, D.W. \& Biorndal, K.A. (2000) Relation of temperature, moisture, salinity, and slope to nest site selection in loggerhead sea turtles. Copeia, 2000, 119-128.

Wootтon, J.T. (1992) Indirect effects, prey susceptibility, and habitat selection: impacts of birds on limpets and algae. Ecology, 73, 981-991.

Zbinden, J.A., Aebischer, A., Margaritoulis, D. \& Arlettaz, R. (2008) Important areas at sea for adult loggerhead sea turtles in the Mediterranean Sea: satellite tracking corroborates findings from potentially biased sources. Marine Biology, 153, 899-906.

\section{Biographical sketches}

Kostas Katselidis is a manager and researcher at the National Marine Park of Zakynthos, specializing in developing sustainable initiatives within the marine, coastal and terrestrial protected area. GAIL SCHOFIELD specializes in marine vertebrate tracking, ecology and conservation, primarily of marine turtle breeding and foraging habitats. GIORGOS STAMOU specializes in population dynamics, life history strategies, social and political ecology, the development of social research methods, and environmental education. PANAYOTIS Dimopoulos specializes in ecology, conservation and management of habitats and species in protected areas, eco-geography and conservation status assessments. JOHN PANTIS specializes in the management and conservation of protected areas, the structure and dynamics of ecosystems, landscape and acoustic ecology, and indices of environmental stress. 